\title{
Assessment of Neutrophil-Lymphocyte Ratios in Patients with Dry Age-related Macular Degeneration
}

NAIF SANNAN ( $\square$ sannann@ksau-hs.edu.sa )

KING SAUD BIN ABDULAZIZ UNIVERSITY FOR HEALTH SCIENCES, JEDDAH

MAJED RAMADHAN

KING ABDULLAH INTERNATIONAL MEDICAL RESEARCH CENTER, JEDDAH

MOHIELDIN ELSAYID

KING SAUD BIN ABDULAZIZ UNIVERSITY FOR HEALTH SCIENCES, JEDDAH

HANAN ALGHAMDI

KING SAUD BIN ABDULAZIZ UNIVERSITY FOR HEALTH SCIENCES, JEDDAH

LAMIS ALGHAMDI

KING SAUD BIN ABDULAZIZ UNIVERSITY FOR HEALTH SCIENCES, JEDDAH

MAHA ALQAHTANI

KING SAUD BIN ABDULAZIZ UNIVERSITY FOR HEALTH SCIENCES, JEDDAH

\section{Research Article}

Keywords: Dry age-related macular degeneration, inflammation, NLR, neutrophil, lymphocytes, biomarkers

Posted Date: November 10th, 2021

DOI: https://doi.org/10.21203/rs.3.rs-965139/v2

License: (c) (i) This work is licensed under a Creative Commons Attribution 4.0 International License.

Read Full License 


\section{Abstract}

Purpose: To assess the significance of neutrophil-lymphocyte ratio (NLR) as an inflammatory indicator in patients with dry age-related macular degeneration (AMD).

Study design: A retrospective case-control study.

Methods: Clinical diagnosis along with complete blood count $(\mathrm{CBC})$ results were extracted from hospital and laboratory information systems for patients with dry-AMD and age/gender-matched controls attending the ophthalmology clinic at King Abdulaziz medical city, Jeddah, Saudi Arabia, between 20182020. NLR was calculated by dividing the neutrophil by the lymphocyte count.

Results: This study captured 90 patients diagnosed with dry-AMD and 270 control subjects without AMD. The mean of ages 70 and 71 years old for cases and controls, respectively. In univariate analysis, there were no significant differences in CBC results between cases and control. In NLR, dry-AMD patients have a slightly higher mean than the control group; however, this increase was not statistically significant ( $P$ value 0.8$)$. In the NLR model, age and gender were statistically significant factors affecting the NLR values in dry-AMD ( $P$-value $0.03,0.01$ respectively).

Conclusion: as a systemic inflammatory biomarker, NLR alone could not predict dry-AMD. However, the slight increase in the NLR values may be helpful if augmented with other laboratory measurements to aid in early disease prediction.

\section{Background}

Age-related macular degeneration (AMD) is the third leading cause of blindness following cataracts and glaucoma (Abner et al., 2002). Yet, it is the leading cause of blindness in patients over 50 years of age (AlGhamdi, 2019; Hajar et al., 2015) and the fourth leading cause of low vision in the Saudi population (Z Alotaibi, 2015). AMD is caused by the accumulation of drusen in the macula with or without geographic atrophy, resulting in different levels of visual impairment and/or blindness. AMD starts dry (nonneovascular or non-exudative) and can progress into the wet form (neovascular or exudative) with or without retinal pigment detachment in the macular region. Wet AMD is responsible for the majority of severe vision loss (Wong et al., 2014).

According to the Saudi General Authority for Statistics (2018 report), over $90 \%$ of the Saudi population is under 50 years of age. With the aging population, the number of AMD patients is expected to increase, which would lead to heavy health, social, and economic burden (Pascolini \& Mariotti, 2012; Wong et al., 2014). The Saudi elderly population ( $\geq 60$ ) is projected to increase from $3 \%$ in 2010 to $9.5 \%$ and $18.4 \%$ in 2035 and 2050, respectively (Khoja et al., 2018). Because of the disease's silent onset, it is rational to investigate potential novel biomarkers to aid in early prediction, diagnosis, and prognosis of AMD. Early detection will ultimately allow proper utilization of the available AMD management options to prevent or slow vision loss. AMD pathogenesis is not yet fully understood. Our knowledge about AMD risk factors is 
limited to a complex of factors such as genetic makeup, environmental stimuli, and metabolic features (Čolak et al., 2018; Velez-Montoya et al., 2014; Zarbin, 2004).

The role of NLR as a simple, reliable, and low-cost inflammatory biomarker in ocular conditions is yet unclear. Several reports have demonstrated a correlation between NLR and wet AMD (Reviewed in Niazi et al., 2019). However, the link between NLR and dry AMD is based on a limited number of studies (llhan et al., 2015; Kurtul \& Ozer, 2016), limiting our insight into the starting phase of the disease. This study aims to assess the levels of NLR in patients with dry AMD.

\section{Methods}

\section{Study population}

Institutional review board and ethics committee approval was obtained from King Abdullah international medical research center (Study number SP21J/083/03). While maintaining participants' confidentiality and anonymity, electronic health records (January 2018 - December 2020) were collected for new patients with dry AMD, $\geq 50$ years, with evidence of macular drusen in at least one eye, with or without signs of geographic atrophy, and complete blood count (CBC) laboratory results. NLR was calculated by dividing the neutrophil $\left(x 10^{9} / \mathrm{L}\right)$ by the lymphocyte $\left(x 10^{9} / \mathrm{L}\right)$ count. Similar data were collected for age and sexmatched cataract group without AMD as a control. Electronic health records were compiled from King Abdulaziz medical city (Jeddah, Saudi Arabia), which provides primary, secondary, and tertiary care. The study was performed following the Declaration of Helsinki principles, and informed consent was obtained from all participants.

\section{Sample size calculation}

The survivor sampling technique was used with a control group consisting of individuals from the source population who do not have the outcome of interest (with no AMD). For sample size calculation, a matched case-control study was used (the case-control ratio is 1:3).

\section{Statistical analysis}

In univariate analysis, associations between demographics and blood results characteristics were assessed across cases and control groups using the chi-square for categorical data and t-test for numeric variables. Multivariate analyses adjusted for age and gender were conducted to examine the differences between cases and control groups. Models were assessed using analysis of covariance according to the nature of our outcome. We checked assumptions of the linear relationship between the dependent variable and the covariate and homogeneity of regression slopes, and all models met the assumptions. $P$ values were two-sided; all confidence intervals were at $95 \%$. All analyses were conducted using the SAS statistical software version 9.4 (SAS Institute Inc. Cary, NC).

\section{Results}


From January 2018 to December 2020, this study captured 90 cases of patients diagnosed with dry AMD and 270 control subjects without AMD. The mean of ages 70 and 71 years old for cases and controls, respectively. $\mathrm{CBC}$ results are summarized in table 1.

In univariate analysis (Table 1), there were no significant differences in $\mathrm{CBC}$ results between cases and control groups. In Platelet results, control groups tend to have a slightly higher mean (268.73) than cases group mean 268.68 with a $P$-value of 0.0001 . In terms of mean corpuscular hemoglobin, the cases group showed a lower mean of 27.9 than the control group, 28.27. In NLR, dry AMD patients have a slightly higher mean than the control group (2.46 and 1.98, respectively). However, this increase was not statistically significant ( $P$-value 0.8$)$. The same pattern was observed in mean corpuscular volume, where the case group showed a lower mean than the control group (86.54 and 86.64, respectively). Regression models adjusted for age and gender were summarized in tables 2-3, and figure 1 . Age and gender were statistically significant factors affecting NLR values in cases compared to the control group ( $P$-value $0.03,0.01$ respectively). No other $\mathrm{CBC}$ parameters showed any significant difference between cases and the control group.

\section{Discussion}

The NLR has been increasingly investigated as a systemic inflammation marker. Several studies have analyzed NLR in inflammatory conditions as an indicator of the disease, progression, and severity. For instance, positive NLR correlation was reported in diabetic retinopathy, worsening renal function in diabetic patients, end-stage renal disease, metabolic syndrome, ulcerative colitis, coronary artery disease, papillary microcarcinomas, pancreatitis, and cardiovascular diseases (Ulu et al., 2013; Azab et al., 2012; Turkmen et al., 2014; Buyukkaya et al., 2014; Okba et al., 2019; Torun et al., 2012; Papa et al., 2008; Seretis et al., 2013; Suppiah et al., 2013; Afari \& Bhat, 2016; Cupp et al., 2020).

In AMD, Ilhan et al. (2015) has reported a significant difference in NLR values between dry and wet AMD $(p=0.017)$, wet AMD and controls $(p<0.001)$, and dry AMD and controls $(p<0.001)$. Other reports have shown that elevated NLR was significantly correlated with wet AMD (Niazi et al., 2019). This study found that NLR values were slightly elevated in dry AMD patients compared to control; however, this was not statistically significant. The slight increase may correlate well with our newly diagnosed patient cohort.

Inflammatory mechanisms have been reported in the progressing of both dry and wet AMD (Xu et al., 2009). The accumulation of drusens between the retinal pigment epithelium and Bruch's membrane is a significant risk factor for the progression of AMD. These pathological drusens can trigger a cascade of chronic inflammatory and immune-mediated processes (Hageman et al., 2001; Rivera et al., 2017). Golestaneh et al. (2017) have shown that impairment in autophagic processes can contribute to drusens accumulation. In addition to the increased reactive oxygen species (ROS) and the reduced mitochondrial activity observed in retinal pigment epithelial cells cultured from human donors with AMD compared to healthy donors. With aging, mitochondria accumulate ROS damage and become dysfunctional, resulting in a notable decline in mitochondrial health, in addition to the decrease of autophagic processes (Picca et 
al., 2017). The accumulation of oxidative damage is believed to be a leading cause of age-related degenerative diseases such as cancer, Alzheimer's disease, and AMD pathological processes (Chen \& Xu, 2015; Datta et al., 2017; Golestaneh et al., 2017; Heppner et al., 2015; Matsui et al., 2000; Saijo et al., 2016).

Furthermore, the damaged mitochondria release components such as mitochondrial DNA (mtDNA), which induces inflammatory responses. A study by Lin et al., (2011) has shown that the increase in age-related mtDNA damage can lead to more macula lesions that positively correlate with AMD progression. Sensing mtDNA by cytosolic innate immune sensors, cyclic-GMP-AMP synthase, and the stimulator of interferon genes, lead to the production of Type I interferons (Type I IFNs) and other pro-inflammatory cytokines (Kumar, 2019). Additionally, mtDNA also triggers the assembly of a multiprotein complex known as the inflammasome (Shimada et al., 2012a). NOD-like receptors, and absent in melanoma 2-like receptors, are the two major sensors known to date responsible for the induction of inflammatory responses via the assembly of the inflammasome. Assembly of the inflammasomes leads to the production of inflammasome-mediated cytokines, IL-1 $\beta$ and IL-18, and eventually the pyroptotic type of cell death (Elinav et al., 2011; Keating et al., 2011). In relevance, mounting evidence suggested that mitochondria play an important role in activating the NOD-like receptors family pyrin domain containing 3 (NLRP3) inflammasome. It has been demonstrated that mitochondrial damage and the cytosolic release of mitochondrial ROS and mtDNA increase NLRP3 activation (Shimada et al., 2012; Zhou R. et al., 2011). Therefore, inflammasome activation by mtDNA and the progression of AMD needs to be investigated. The role of the NLRP3 inflammasome in AMD pathogenesis has been shown using the amyloid-beta (A $\beta$ ) component of drusen as a stimulus which resulted in a robust inflammasome activation evident by elevated levels of IL-1 $\beta$ and IL-18. In addition to inflammasome-mediated-cytokines, stimulation with A $\beta$ resulted in upregulation of the pro-inflammatory cytokines, IL-6 and TNF-a (Liu et al., 2013). Therefore, further studies are essential to investigate the levels of inflammatory markers including type I IFNs, IL-1 $\beta$, IL-18, IL-6, and TNF- $a$ in patients with dry and wet AMD compared to control participants.

\section{Conclusion}

As a routine laboratory test, it is important to note that NLR is not specific for either type of AMD and can be elevated in several diseases and malignancies. The disease is also often associated with other agedependent comorbidities, which could influence NLR values. Therefore, further studies are essential to generate robust evidence to investigate causality and NLR values clinical utility in line with other inflammatory biomarkers.

\section{Abbreviations}

AMD

age-related macular degeneration

$\mathrm{A} \beta$

amyloid-beta 
$\mathrm{CBC}$

complete blood count

IFNs

interferons

IL

Interleukins

mtDNA

mitochondrial DNA

NLR

Neutrophil-lymphocyte ratio

NLRP3

NOD-like receptors family pyrin domain containing 3

ROS

reactive oxygen species

\section{Declarations}

Ethics approval and consent to participate: IRB approval was obtained from King Abdulla international medical research center (\#SP21 J/083/03).

Consent for publication: Not applicable

Availability of data and materials: provided

Competing interests: None

Funding: Not funded

Authors' contributions: all authours were heavily involved in data collection, analysis and manuscript preparation.

Acknowledgements: None

\section{References}

1. Abner, G. H., Lahm, E. A., Islam, J., Mario, S. P., Mary, F., Siu, D. A. Y., Myhill, C. E., Stevens, G. A., White, R. A., Flaxman, S. R., Price, H., Jonas, J. B., Keeffe, J., Leasher, J., Naidoo, K., Pesudovs, K., Resnikoff, S., Taylor, H., Bourne, R. R., \& UNESCO. (2002). Global Data on Visual Impairments 2010. In Journal of Visual Impairment \& Blindness. https://doi.org/http://dx.doi.org/10.1016/j.ophtha.2013.05.025 2377

2. Al-Ghamdi, A. S. (2019). Adults visual impairment and blindness - An overview of prevalence and causes in Saudi Arabia. Saudi Journal of Ophthalmology. 
https://doi.org/10.1016/j.sjopt.2019.10.001

3. Azab, B., Daoud, J., Naeem, F. Ben, Nasr, R., Ross, J., Ghimire, P., Siddiqui, A., Azzi, N., Rihana, N., Abdallah, M., Azzi, N., Patel, P., Kleiner, M., \& El-Sayegh, S. (2012). Neutrophil-to-lymphocyte ratio as a predictor of worsening renal function in diabetic patients (3-year follow-up study). Renal Failure, 34(5), 571-576. https://doi.org/10.3109/0886022X.2012.668741

4. Buyukkaya, E., Karakas, M. F., Karakas, E., Akçay, A. B., Tanboga, I. H., Kurt, M., \& Sen, N. (2014). Correlation of neutrophil to lymphocyte ratio with the presence and severity of metabolic syndrome. Clinical and Applied Thrombosis/Hemostasis: Official Journal of the International Academy of Clinical and Applied Thrombosis/Hemostasis, 20(2), 159-163. https://doi.org/10.1177/1076029612459675

5. Chen, M., \& Xu, H. (2015). Parainflammation, chronic inflammation and age-related macular degeneration. Journal of Leukocyte Biology, 98(5), 713. https://doi.org/10.1189/JLB.3RI0615-239R

6. Čolak, E., Žorić, L., Radosavljević, A., \& Ignjatović, S. (2018). The Association of Serum Iron-Binding Proteins and the Antioxidant Parameter Levels in Age-Related Macular Degeneration. Current Eye Research. https://doi.org/10.1080/02713683.2018.1437452

7. Datta, S., Cano, M., Ebrahimi, K., Wang, L., \& Handa, J. T. (2017). The Impact of Oxidative Stress and Inflammation on RPE Degeneration in Non-neovascular AMD. Progress in Retinal and Eye Research, 60, 201. https://doi.org/10.1016/J.PRETEYERES.2017.03.002

8. Elinav, E., Strowig, T., Henao-Mejia, J., \& Flavell, R. A. (2011). Regulation of the Antimicrobial Response by NLR Proteins. In Immunity (Vol. 34, Issue 5, pp. 665-679). https://doi.org/10.1016/j.immuni.2011.05.007

9. Golestaneh, N., Chu, Y., Xiao, Y. Y., Stoleru, G. L., \& Theos, A. C. (2017). Dysfunctional autophagy in RPE, a contributing factor in age-related macular degeneration. Cell Death and Disease. https://doi.org/10.1038/cddis.2016.453

10. Hageman, G. S., Luthert, P. J., Victor Chong, N. H., Johnson, L. V, Anderson, D. H., \& Mullins, R. F. (2001). An integrated hypothesis that considers drusen as biomarkers of immune-mediated processes at the RPE-Bruch's membrane interface in aging and age-related macular degeneration. Progress in Retinal and Eye Research, 20(6), 705-732. https://doi.org/10.1016/s13509462(01)00010-6

11. Hajar, S., Hazmi, A. Al, Wasli, M., Mousa, A., \& Rabiu, M. (2015). Prevalence and causes of blindness and diabetic retinopathy in southern Saudi Arabia. Saudi Medical Journal. https://doi.org/10.15537/smj.2015.4.10371

12. Heppner, F. L., Ransohoff, R. M., \& Becher, B. (2015). Immune attack: the role of inflammation in Alzheimer disease. Nature Reviews. Neuroscience, 16(6), 358-372. https://doi.org/10.1038/nrn3880

13. Ilhan, N., Daglioglu, M. C., Ilhan, O., Coskun, M., Tuzcu, E. A., Kahraman, H., \& Keskin, U. (2015). Assessment of Neutrophil/Lymphocyte Ratio in Patients with Age-related Macular Degeneration. Ocular Immunology and Inflammation, 23(4), 287-290. https://doi.org/10.3109/09273948.2014.921715 
14. Keating, S. E., Baran, M., \& Bowie, A. G. (2011). Cytosolic DNA sensors regulating type I interferon induction. In Trends in Immunology (Vol. 32, Issue 12, pp. 574-581). https://doi.org/10.1016/j.it.2011.08.004

15. Khoja, A. T., Aljawadi, M. H., Al-Shammari, S. A., Mohamed, A. G., Al-Manaa, H. A., Morlock, L., Ahmed, S., \& Khoja, T. A. M. (2018). The health of Saudi older adults; results from the Saudi National Survey for Elderly Health (SNSEH) 2006-2015. Saudi Pharmaceutical Journal: SPJ: The Official Publication of the Saudi Pharmaceutical Society, 26(2), 292-300. https://doi.org/10.1016/j.jsps.2017.11.008

16. Kumar, V. (2019). A STING to inflammation and autoimmunity. In Journal of Leukocyte Biology (Vol. 106, Issue 1, pp. 171-185). John Wiley and Sons Inc. https://doi.org/10.1002/JLB.4MIR1018-397RR

17. Kurtul, B. E., \& Ozer, P. A. (2016). The Relationship between Neutrophil-to-lymphocyte Ratio and Agerelated Macular Degeneration. Korean Journal of Ophthalmology: KJO, 30(5), 377-381. https://doi.org/10.3341/kjo.2016.30.5.377

18. Lin, H., Xu, H., Liang, F.-Q., Liang, H., Gupta, P., Havey, A. N., Boulton, M. E., \& Godley, B. F. (2011). Mitochondrial DNA Damage and Repair in RPE Associated with Aging and Age-Related Macular Degeneration. Investigative Ophthalmology \& Visual Science, 52(6), 3521-3529. https://doi.org/10.1167/IOVS.10-6163

19. Liu, R. T., Gao, J., Cao, S., Sandhu, N., Cui, J. Z., Chou, C. L., Fang, E., \& Matsubara, J. A. (2013). Inflammatory Mediators Induced by Amyloid-Beta in the Retina and RPE In Vivo: Implications for Inflammasome Activation in Age-Related Macular Degeneration. Investigative Ophthalmology \& Visual Science, 54(3), 2225. https://doi.org/10.1167/IOVS.12-10849

20. Matsui, A., Ikeda, T., Enomoto, K., Hosoda, K., Nakashima, H., Omae, K., Watanabe, M., Hibi, T., \& Kitajima, M. (2000). Increased formation of oxidative DNA damage, 8-hydroxy-2'-deoxyguanosine, in human breast cancer tissue and its relationship to GSTP1 and COMT genotypes. Cancer Letters, 151(1), 87-95. https://doi.org/10.1016/s0304-3835(99)00424-3

21. Niazi, S., Krogh Nielsen, M., Sørensen, T. L., \& Subhi, Y. (2019). Neutrophil-to-lymphocyte ratio in agerelated macular degeneration: a systematic review and meta-analysis. Acta Ophthalmologica, 97(6), 558-566. https://doi.org/https://doi.org/10.1111/aos.14072

22. Okba, A. M., Amin, M. M., Abdelmoaty, A. S., Ebada, H. E., Kamel, A. H., Allam, A. S., \& Sobhy, O. M. (2019). Neutrophil/lymphocyte ratio and lymphocyte/monocyte ratio in ulcerative colitis as noninvasive biomarkers of disease activity and severity. Auto-Immunity Highlights, 10(1), 4. https://doi.org/10.1186/s13317-019-0114-8

23. Papa, A., Emdin, M., Passino, C., Michelassi, C., Battaglia, D., \& Cocci, F. (2008). Predictive value of elevated neutrophil-lymphocyte ratio on cardiac mortality in patients with stable coronary artery disease. Clinica Chimica Acta; International Journal of Clinical Chemistry, 395(1-2), 27-31. https://doi.org/10.1016/j.cca.2008.04.019

24. Pascolini, D., \& Mariotti, S. P. (2012). Global estimates of visual impairment: 2010. British Journal of Ophthalmology. https://doi.org/10.1136/bjophthalmol-2011-300539 
25. Picca, A., Lezza, A. M. S., Leeuwenburgh, C., Pesce, V., Calvani, R., Landi, F., Bernabei, R., \& Marzetti, E. (2017). Fueling inflamm-aging through mitochondrial dysfunction: Mechanisms and molecular targets. In International Journal of Molecular Sciences (Vol. 18, Issue 5). MDPI AG. https://doi.org/10.3390/ijms18050933

26. Rivera, J. C., Dabouz, R., Noueihed, B., Omri, S., Tahiri, H., \& Chemtob, S. (2017). Ischemic Retinopathies: Oxidative Stress and Inflammation. Oxidative Medicine and Cellular Longevity, 2017, 3940241. https://doi.org/10.1155/2017/3940241

27. Saijo, H., Hirohashi, Y., Torigoe, T., Horibe, R., Takaya, A., Murai, A., Kubo, T., Kajiwara, T., Tanaka, T., Shionoya, Y., Yamamoto, E., Maruyama, R., Nakatsugawa, M., Kanaseki, T., Tsukahara, T., Tamura, Y., Sasaki, Y., Tokino, T., Suzuki, H., Sato, N. (2016). Plasticity of lung cancer stem-like cells is regulated by the transcription factor HOXA5 that is induced by oxidative stress. Oncotarget, 7(31), 5004350056. https://doi.org/10.18632/oncotarget.10571

28. Saudi General Authority for Statistics. (2018). General Authority for Statistics. Stats.Gov.Sa/En/. https://www.stats.gov.sa/en/5680

29. Seretis, C., Gourgiotis, S., Gemenetzis, G., Seretis, F., Lagoudianakis, E., \& Dimitrakopoulos, G. (2013). The significance of neutrophil/lymphocyte ratio as a possible marker of underlying papillary microcarcinomas in thyroidal goiters: a pilot study. American Journal of Surgery, 205(6), 691-696. https://doi.org/10.1016/j.amjsurg.2012.08.006

30. Shimada, K., Crother, T. R., Karlin, J., Dagvadorj, J., Chiba, N., Chen, S., Ramanujan, V. K., Wolf, A. J., Vergnes, L., Ojcius, D. M., Rentsendorj, A., Vargas, M., Guerrero, C., Wang, Y., Fitzgerald, K. A., Underhill, D. M., Town, T., \& Arditi, M. (2012a). Oxidized Mitochondrial DNA Activates the NLRP3 Inflammasome during Apoptosis. Immunity, 36(3), 401-414. https://doi.org/10.1016/j.immuni.2012.01.009

31. Shimada, K., Crother, T. R., Karlin, J., Dagvadorj, J., Chiba, N., Chen, S., Ramanujan, V. K., Wolf, A. J., Vergnes, L., Ojcius, D. M., Rentsendorj, A., Vargas, M., Guerrero, C., Wang, Y., Fitzgerald, K. A., Underhill, D. M., Town, T., \& Arditi, M. (2012b). Oxidized Mitochondrial DNA Activates the NLRP3 Inflammasome during Apoptosis. Immunity, 36(3), 401-414. https://doi.org/10.1016/j.immuni.2012.01.009

32. Suppiah, A., Malde, D., Arab, T., Hamed, M., Allgar, V., Smith, A. M., \& Morris-Stiff, G. (2013). The prognostic value of the neutrophil-lymphocyte ratio (NLR) in acute pancreatitis: identification of an optimal NLR. Journal of Gastrointestinal Surgery: Official Journal of the Society for Surgery of the Alimentary Tract, 17(4), 675-681. https://doi.org/10.1007/s11605-012-2121-1

33. Torun, S., Tunc, B. D., Suvak, B., Yildiz, H., Tas, A., Sayilir, A., Ozderin, Y. O., Beyazit, Y., \& Kayacetin, E. (2012). Assessment of neutrophil-lymphocyte ratio in ulcerative colitis: a promising marker in predicting disease severity. Clinics and Research in Hepatology and Gastroenterology, 36(5), 491497. https://doi.org/10.1016/j.clinre.2012.06.004

34. Turkmen, K., Ozcicek, F., Ozcicek, A., Akbas, E. M., Erdur, F. M., \& Tonbul, H. Z. (2014). The relationship between neutrophil-to-lymphocyte ratio and vascular calcification in end-stage renal disease patients. Hemodialysis International. International Symposium on Home Hemodialysis, 18(1), 47-53. https://doi.org/10.1111/hdi.12065 
35. Velez-Montoya, R., Oliver, S. C. N., Olson, J. L., Fine, S. L., Quiroz-Mercado, H., \& Mandava, N. (2014). Current knowledge and trends in age-related macular degeneration: Genetics, epidemiology, and prevention. In Retina. https://doi.org/10.1097/IAE.0000000000000036

36. Wong, W. L., Su, X., Li, X., Cheung, C. M. G., Klein, R., Cheng, C. Y., \& Wong, T. Y. (2014). Global prevalence of age-related macular degeneration and disease burden projection for 2020 and 2040: A systematic review and meta-analysis. The Lancet Global Health. https://doi.org/10.1016/S2214109X(13)70145-1

37. Xu, H., Chen, M., \& Forrester, J. V. (2009). Para-inflammation in the aging retina. Progress in Retinal and Eye Research, 28(5), 348-368. https://doi.org/https://doi.org/10.1016/j.preteyeres.2009.06.001

38. Z Alotaibi, A. (2015). A Retrospective Study of Causes of Low Vision in Saud Arabia, A Case of Eye World Medical Complex in Riyadh. Global Journal of Health Science. https://doi.org/10.5539/gjhs.v8n5p205

39. Zarbin, M. A. (2004). Current Concepts in the Pathogenesis of Age-Related Macular Degeneration. In Archives of Ophthalmology. https://doi.org/10.1001/archopht.122.4.598

40. Zhou, R., Yazdi, A. S., Menu, P., \& Tschopp, J. (2011). A role for mitochondria in NLRP3 inflammasome activation. Nature, 469(7329), 221-226. https://doi.org/10.1038/nature09663

\section{Tables}




\begin{tabular}{|c|c|c|c|}
\hline & $\begin{array}{l}\text { dry AMD } \\
\mathrm{n}(\%)^{1}\end{array}$ & $\begin{array}{l}\text { Controls } \\
\text { n (\%) }\end{array}$ & $\begin{array}{l}p \text {-value cases vs. } \\
\text { controls }^{2}\end{array}$ \\
\hline Total & $90(22.55)$ & $270(77.44)$ & - \\
\hline Age, years, mean \pm SD & $71 \pm 9$ & $70 \pm 7$ & 0.27 \\
\hline \multicolumn{4}{|l|}{ Gender } \\
\hline Male & $41(45.56)$ & $132(42.72)$ & 0.63 \\
\hline Female & $49(54.44)$ & $177(57.28)$ & \\
\hline Hematological parameters & \multicolumn{2}{|c|}{ Means (upper,lower) } & \\
\hline Red blood cells $\left(10^{12} / \mathrm{l}\right)$ & $4.66(4.55,4.78)$ & $4.56(4.5,4.62)$ & 0.21 \\
\hline Hemoglobin (g/dl) & $\begin{array}{l}14.34(11.92, \\
16.77)\end{array}$ & $\begin{array}{l}13.25(12.63 \\
13.87)\end{array}$ & 0.49 \\
\hline Mean Corpuscular Hemoglobin (pg) & $\begin{array}{l}27.9(27.37 \\
28.42)\end{array}$ & $\begin{array}{l}28.27(27.97 \\
28.56)\end{array}$ & 0.9 \\
\hline Mean corpuscular volume (fL) & $\begin{array}{l}86.4(84.5 \\
88.37)\end{array}$ & $85.8(84.5,86.1)$ & 0.43 \\
\hline White blood cells $\left(10^{9} / \mathrm{I}\right)$ & $7.71(7.07,8.34)$ & $7.95(7.47,8.44)$ & 0.21 \\
\hline Platelet $\left(10^{9} / \mathrm{I}\right)$ & $\begin{array}{l}268.61(254.23 \\
283)\end{array}$ & $\begin{array}{l}268.73(260.168 \\
277.31)\end{array}$ & $<0.0001$ \\
\hline Mean platelet volume (fL) & $8.35(8.12,8.57)$ & $8.28(8.17,8.39)$ & 0.87 \\
\hline Red cell distribution width (\%) & $\begin{array}{l}13.91(13.57 \\
14.24)\end{array}$ & $\begin{array}{l}14.31(13.63 \\
14.98)\end{array}$ & 0.11 \\
\hline $\begin{array}{l}\text { Mean corpuscular hemoglobin } \\
\text { concentration }(\mathrm{g} / \mathrm{dl})\end{array}$ & $\begin{array}{l}36.97(30.27 \\
43.67)\end{array}$ & $\begin{array}{l}34.36(32.21 \\
36.52)\end{array}$ & 0.74 \\
\hline Eosinophils $\left(10^{9} / \mathrm{I}\right)$ & $0.52(0.28,0.76)$ & $1.61(-0.65,3.86)$ & 0.62 \\
\hline Monocytes $\left(10^{9} / \mathrm{I}\right)$ & $0.63(0.57,0.68)$ & $0.602(0.57,0.62)$ & 0.63 \\
\hline Neutrophils $\left(10^{9} / \mathrm{I}\right)$ & $4.55(3.75,5.32)$ & $4.2(3.76,5.63)$ & 0.79 \\
\hline Lymphocytes $\left(10^{9} / \mathrm{I}\right)$ & $2.29(2.11,2.47)$ & $2.39(2.31,2.48)$ & 0.44 \\
\hline Neutrophil-to-lymphocyte ratio (NLR) & $2.46(0.43,0.77)$ & $1.98(0.33,0.48)$ & 0.02 \\
\hline Monocyte-to-lymphocyte ratio (MLR) & $\begin{array}{l}0.327(0.28 \\
0.37)\end{array}$ & $0.326(0.29,0.35)$ & 0.9 \\
\hline Platelet/lymphocyte ratio (PLR) & $141.41(127.47$ & $132.87(124.54$ & 0.07 \\
\hline
\end{tabular}


1 "n" sample size, \% percentage

2 Chi-square test for categorical variables, and t-test numeric variables

Table.2 Regression analysis for predicting factors associated with change of dry AMDcases and controls (adjusted for age, gender)

\section{Hematological parameters}

Red blood cells

Hemoglobin

Mean Corpuscular Hemoglobin

Mean corpuscular volume

White blood cells

Platelet

Mean platelet volume

Red cell distribution width

Mean corpuscular hemoglobin concentration

Eosinophils

Monocytes

Neutrophils

Lymphocytes

Neutrophil-to-lymphocyte ratio (NLR)

Monocyte-to-lymphocyte ratio (MLR)

Platelet/lymphocyte ratio (PLR)

dry AMD Controls

Standard error

Beta coefficient ( $\beta$ )

$\begin{array}{ll}\text { Beta } & \text { Standard error } \\ \text { coefficient ( } \beta) & (\mathrm{SE})\end{array}$

p-values cases vs controls 1 
Table.3 Regression analysis for predicting factors associated with change of dry AMD cases and controls (adjusted for age, gender)

Cases of dry AMD vs controls

Beta coefficient

( $\beta$ )
Standard error

(SE)

\section{Neutrophil-to-lymphocyte ratio}

(NLR)

$-0.13$

0.08

0.13

p-value cases vs controls 1

Age

0.67

0.31

$0.03^{*}$

\section{Gender}

Male

Reference

Reference

Female

$-0.17$

0.072

0.016 *

1 ANCOVA used to estimate differences in covariances across patients with dry AMD and without AMD, adjusted for age and gender,

*Statistically significant.

\section{Figures}

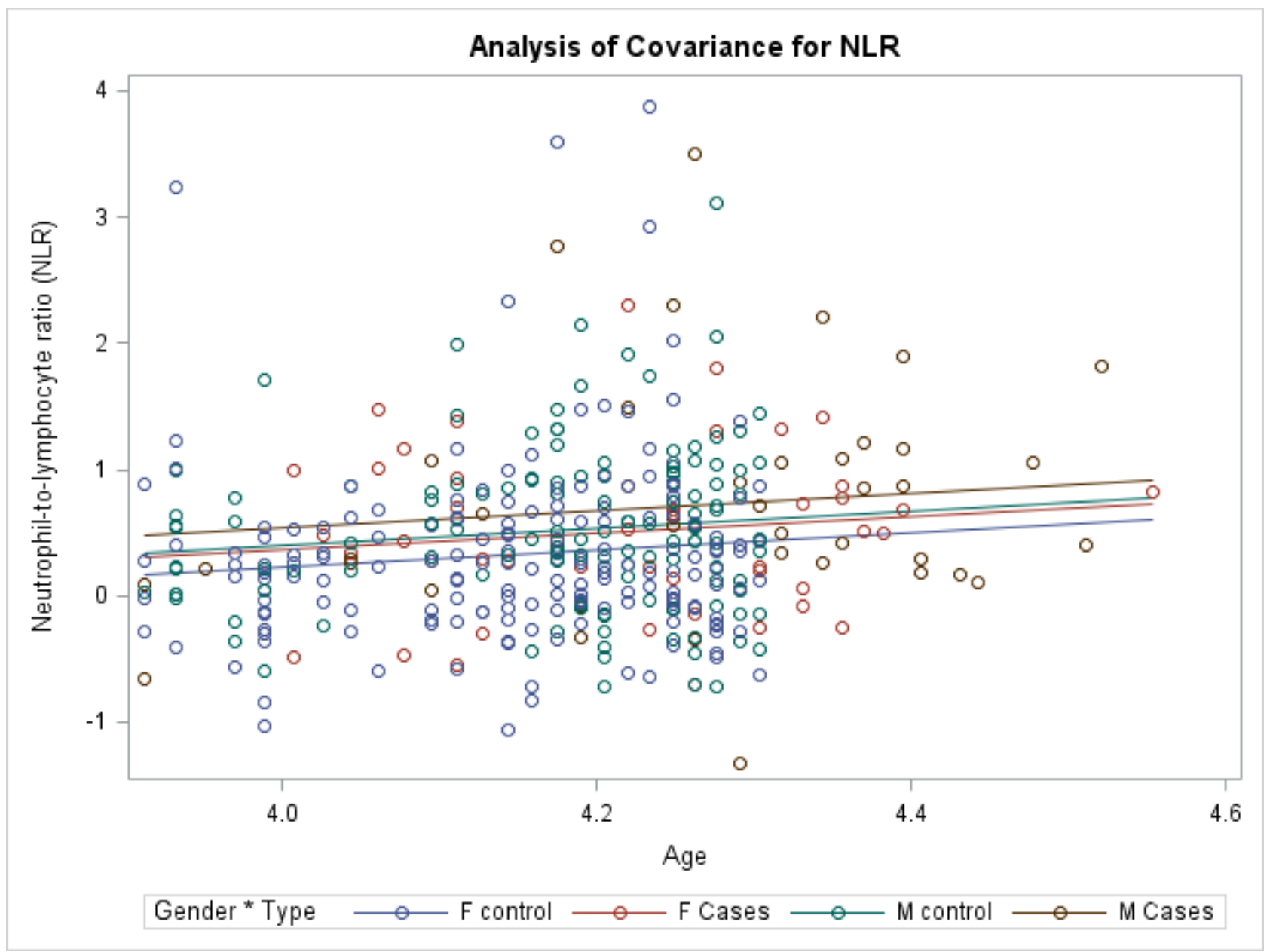




\section{Figure 1}

Analysis of covariance for NLR 